\title{
An Alternative Approach to Decomposing the Redistributive Effect of Health Financing Between and Within Groups Using the Gini Index: The Case of Out-of-Pocket Payments in Nigeria
}

\author{
John E. Ataguba' ${ }^{1}$. Hyacinth E. Ichoku² Chijioke O. Nwosu $^{3} \cdot$ James Akazili $^{4}$
}

Published online: 18 October 2019

(c) The Author(s) 2019

\begin{abstract}
Equity in health financing remains significant in the universal health coverage discourse. The way a health system is financed, apart from determining whether people have access to needed health services, also has implications for income inequality in a country. Traditionally, the impact of health financing on income inequality or the redistributive effect of health financing is assessed by looking at whether income inequality reduces because of health financing. This is also decomposed into a vertical component (the extent of progressivity), a horizontal component (the extent to which households with similar incomes are treated equally when financing health services) and a reranking component (whether households change their relative socio-economic ranking after financing health services). Such an approach to decomposition is mainly essential to assess the equal treatment of equals and unequal treatment of unequals in the entire population. This paper argues that in decomposing the redistributive effect of health financing, the impact of health financing on changes in income inequality between and within population groups should be investigated as they are relevant for policy dialogues in many countries. It develops a framework for such analysis and applies this to data from Nigeria. Decomposing the Gini index of income inequality using the Shapley value approach, the results show that changes in inequality associated with out-of-pocket payments for health services within the geopolitical zones in Nigeria dominate the changes in income inequality between the geopolitical zones. Although not all the results in the application in this paper are statistically significant, this framework is still useful for policies in countries that aim to use health financing to reduce, among other things, income disparities between and within defined population groups.
\end{abstract}

\section{Introduction}

Health financing is a significant area of interest in many countries, including countries in Africa. It is central to the debates about Universal Health Coverage (UHC) and the

John E. Ataguba

john.ataguba@uct.ac.za

1 Health Economics Unit, School of Public Health and Family Medicine, Health Sciences Faculty, University of Cape Town, Anzio Road, Observatory, Cape Town 7925, South Africa

2 Office of the Vice Chancellor, Veritas University, Abuja, Nigeria

3 Economic Performance and Development Unit, Human Sciences Research Council, Cape Town, South Africa

4 Research and Development Division of Ghana Health Service, Accra, Ghana
Sustainable Development Goals (SDGs) [1, 2]. Countries finance health services via various health financing mixes. The most prominent mechanisms used in multiple countries, apart from external funding, include direct out-of-pocket payments, general taxes, private and social health insurance and earmarked taxes. Many African countries tend to rely heavily on direct out-of-pocket payments [3], which comprise payments made at the point of health service utilisation, whether public or private health services. The dominance of such payments in Africa over general taxes and health insurance means that many households may be impoverished and/or face financial catastrophe because of seeking healthcare $[4,5]$. In fact, in many instances, direct out-of-pocket payments are regressive, placing a more substantial burden on the poor than on the rich [2]. In some case, out-of-pocket payments may be progressive [6,7] mainly because the poor cannot afford the cost of healthcare and so avoid using health services altogether. 


\section{Key Points for Decision Makers}

The assessment of how health financing affects income inequality should assess the impact between and within different population groups that are relevant for policy dialogues in many countries.

Health financing can be a tool to reduce income inequalities between and within population groups in countries.

In Nigeria, out-of-pocket payments for health services should be minimised as they currently dominate current health expenditures and contribute to increasing income inequality, especially within the geopolitical zones in the country.

Generally, the way health systems are financed has implications for reductions in income inequality [8]. Regressive financing mechanisms tend to increase income inequalities while progressive financing mechanisms reduce income inequality. Thus, health financing has the potentials to contribute to the widening or reductions in existing income inequalities in countries, depending on the burden it places on the poor relative to the rich. Rigorous analysis of inequalities in health financing is needed to make clear their implied redistributive consequences [9].

Acknowledging previous studies that assess the redistributive effect of health financing [8,10-13], this paper aims to develop a conceptual framework to re-assess the impact of health financing on income inequality with different (i.e. non-overlapping) population groups. The framework builds on the work initially done by Musgrave and Thin [14] and Reynolds and Smolensky [15] where redistribution associated with taxes (including health financing) is the difference between income inequality (whatever the measure) before and after taxation (or health financing). The seminal framework for decomposing the redistributive effect of taxes proposed by Aronson et al. [16] and other variants, have dominated the literature, including the health financing literature. Specifically, this paper departs from that framework and proposes an alternative framework for the decomposition of the redistributive effect of health financing into between groups and within groups. These mutually exclusive groups may include rural/urban location, provinces, counties, etc. These groups are essential in different contexts for policy formulation and provide areas where policy may be used to improve equity in health financing. The proposed framework is applied to data from Nigeria to assess the impact of health financing on income inequality between groups and within groups defined by the six-geopolitical zones.

\section{Conceptual Framework}

Borrowing from tax equity literature, we define $I_{X}$ as a measure of prepayment income inequality. Here, prepayment income is income gross of taxes (e.g. direct taxes and indirect taxes) and healthcare payments (e.g. out-of-pocket payments and private health insurance) [17]. We also define $I_{N}$ as the same measure of income inequality, but net of taxes and healthcare payments. This is called post-payment income. Musgrave and Thin [14] and later refinements [15, 18] define income redistribution associated with taxes (and by extension, healthcare payments) $(R E)$ as:

$\Delta I=R E=I_{X}-I_{N}$,

where $R E>0$ means that inequality in post-payment income is lower than that in prepayment income. Expressed differently, this is a pro-poor redistribution, which involves the redistribution of income from the rich to the poor. Conversely, $R E<0$ signifies a pro-rich redistribution of income from the poor to the rich. A proportional redistribution arises when $R E=0$ such that redistribution leaves the post-payment income distribution unaltered (at least in principle).

In a seminal paper, Aronson et al. [16] (hereafter referred to as AJL) then showed that $R E$ can be decomposed into three components $(V, H$ and $R)$ :

$R E=I_{X}-I_{N}=V-H-R$,

where $V$ represents vertical redistribution (i.e. the extent to which a financing mechanism or system is progressive or regressive). $V$ also measures the tendency of a financing system to 'compress' the distribution of net incomes [19]. Horizontal inequity is captured by $H$ whereas $R$ is the extent of reranking defined in the 'classical sense' as a change in the order of income distribution that results from paying for health services. While there have been debates regarding the distinct nature of reranking and horizontal inequity (see $[19,20])$, it is now relatively clear that reranking relates to the "improper treatment of unequals" [21] or how post-payment income ranks do not correlate with prepayment income ranks. Horizontal inequity, on the other hand, is related to unfair treatment of equals [20].

In applications, including in health economics, different measures of income inequality have been used for the decomposition in Eq. (2). These include the Gini index (see, for example, $[16,22,23]$ ) and the Atkinson-type measure of income inequality [24]. There are challenges with the use of either the Gini index-based decomposition within the AJL framework or the Atkinson-type inequality decomposition. The Gini index-based decomposition requires that households are categorised into groups with "equal" incomes for the estimation of the horizontal and reranking effects, which is practically difficult while the Atkinson-type inequality decomposition involves the use of a concave isoelastic utility 
function and a dual-parameter $(\varepsilon$ and $\nu$ ) social welfare function where $\varepsilon$ is a parameter of aversion to horizontal inequality or relative risk aversion and $v$ is a parameter of aversion to reranking or rank inequality. Among other things, the choice of values for the dual parameters affects the inequality estimate [10].

This paper argues that although the decomposed components of the changes in income inequality (reranking, horizontal and vertical inequity) are essential, the decomposition of the redistributive effect of health financing can be made more policy-relevant in many contexts including Africa where group differences play an important role in policy dialogues. Many African countries are pluralistic societies that deal with divisions and polarisations among different groups-racial, religious, ethnic and regional groupings, including class [25]. Thus, a detailed understanding of how health financing affects between groups and within groups income inequality will also provide a richer context for health financing policy in Africa in addition to the traditional decomposition frameworks using Eq. (2).

\section{An Alternative Approach to Assessing the Redistributive Effect of Health Financing}

Inequality decomposition by subgroup relates to the process through which "the total inequality of a population can be broken down into a weighted average of the inequality existing within subgroups of the population and the inequality existing between them" ([26], p. 901). Traditionally, the Gini index $[27,28]$ was not considered an additively decomposable inequality index between population groups. This is mainly because of the possibility of overlaps in income distribution between subgroups [26]. In the absence of overlaps in income distribution between population subgroups, the Gini index can be decomposed easily into inequality between and within groups. Notwithstanding the limitation in decomposing the Gini index where income distribution overlaps between subgroups, there have been several attempts at decomposing the Gini index into subgroups [29-35]. These studies attempt to decompose inequality using an analytical approach. Compared to indices such as those based on entropy (e.g. the Theil index), for instance, that can be decomposed exactly into the sum of two components (between and within group), the decomposition of the Gini index into subgroups typically includes the addition of a third component for overlapping of incomes (or ranks of income) between groups [36]. The Gini index remains the widely used index of income inequality, thus making it important to provide some way to decompose changes in the index.
Depending on the authors, the Gini index $(G)$ is decomposed into three major components (1) inequality that exists between groups $\left(G^{B}\right)$, (2) the inequality that exists within groups $\left(G^{W}\right)$ and (3) a residual or an overlapping component $\left(G^{R}\right)$. There seems to be a high level of convergence in the definitions of $G^{B}, G^{W}$ and $G^{R}$ as suggested by different authors [36]. So, for brevity, we can write the decomposition of the Gini index by population subgroups as:

$G=G^{B}+G^{W}+G^{R}$,

where $G^{B}$, the between-groups Gini index, is that obtained when every household or individual's income in every subgroup (e.g. rural and urban) is replaced by the relevant subgroup mean income. $G^{W}$, the within group inequality, is obtained as the product of the population share and income share going to each subgroup and the Gini index for income within each subgroup. The overlapping component or the residual $\left(G^{R}\right)$ is very difficult to interpret because it contains elements of the between-group and within-group income inequality. The estimate of the overlapping component will become zero if the subgroup income ranges do not overlap [35]. If an exact decomposition $\left(G=G^{B}+G^{W}\right)$ is desired, either $G^{W}$ or $G^{B}$ is computed in addition to $G$ and the other component is obtained as a 'residual'. In that case, especially in the case where there is an overlap in the distribution of income between groups, depending on which of the components (i.e. $G^{W}$ or $G^{B}$ ) that is computed initially, it is possible to show that the other component that was not estimated directly overlaps with or contains some information about the other component that was estimated directly [37].

While this 'traditional' decomposition approach poses a challenge depending on which index is computed first, a Shapley value decomposition approach does not require a specific order of computation (i.e. computing $G^{W}$ before $G^{B}$ or computing $G^{B}$ before $G^{W}$ ) as it accommodates any of the possibilities. Also, its components are additive [38]. With this appeal, it is only recently that researchers have explored the importance of the Shapley value [39] in the decomposition of the Gini index (and indeed many indices of inequality). In fact, this Shapley value approach, used elsewhere [40, 41] is proposed here as an alternative approach to decompose the redistributive effect of health financing between population subgroups.

\subsection{The Shapley Value Decomposition Approach}

The Shapley value approach "defines an inequality measure as an aggregation (ideally a sum) of a set of contributory factors, whose marginal effects are accounted eliminating each of them in sequence and computing the average of the marginal contributions in all possible elimination sequences" ([42], p. 511). Stated differently, the Shapley value approach 
is about assessing how much inequality would reduce if one of the "factors" (e.g. between-group or within-group inequality) that contribute to inequality is removed or eliminated [19].

The Shapley value approach to decomposition, in this case, involves two broad steps. Firstly, the Gini index is decomposed into $G^{W}$ and $G^{B}$. Next, $G^{W}$ (i.e. 'global' within-group inequality) is expressed as a sum of the within-group contribution of each of the groups [19]. For example, if there are three population subgroups, then $G^{W}=G_{1}^{W}+G_{2}^{W}+G_{3}^{W}$. In general, for $N$ population subgroups, we have $G^{W}=\sum_{i=1}^{N} G_{i}^{W}$ where $G_{i}^{W}$ is the decomposed inequality within group $i$. This is explained in detail later.

Briefly, let us consider $k$ non-overlapping population subgroups (e.g. rural and urban) where $k=\{1, \ldots, K\}$ and each group has a total of $n(k)$ individuals. If $y(k)$ represents a vector of group $k$ 's income, $\mu(k)$ the corresponding mean income for group $k$ and $\mu$ the overall mean income, using the Shapley value approach, total inequality (Gini index) can be written conveniently as:

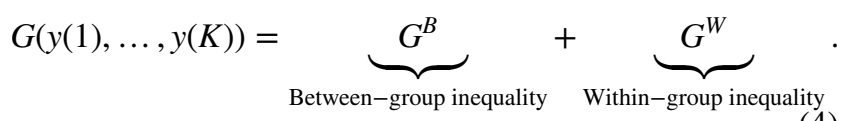

The computation of between-group inequality $\left(G^{B}\right)$ involves the elimination of within-group inequality. This is done by using a vector of income in which every household or everyone's income is replaced by the group's average income $\mu(k)$. Similarly, the computation of within-group inequality $\left(G^{W}\right)$ involves the elimination of between-group inequality using a vector of income where every household or everyone's income is multiplied by the ratio $\left(\frac{\mu(k)}{\mu}\right)$. By implication, both within-group and between-group inequality can be eliminated when every individual's income is replaced with $\mu$ [19]. Because the order in which each factor is eliminated affects the estimates, the Shapley value simply involves computing the average marginal effect of removing a factor across all factor eliminations [19].

Between-group inequality is computed as:

$G^{B}=\frac{1}{2}\left[G(y(1), \ldots, y(K))-G\left(\frac{\mu(k)}{\mu} \cdot y(k)\right)+G(\mu(k))-0\right]$.

Similarly, within-group inequality can be computed as:

$G^{W}=\frac{1}{2}\left[G(y(1), \ldots, y(K))-G(\mu(k))+G\left(\frac{\mu(k)}{\mu} \cdot y(k)\right)-0\right]$.

As noted above, total within-group inequality can be decomposed further as the sum of within-group inequality across the $k$ groups. The Shapley value of group $k$ 's contribution to total within-group inequality can be obtained by replacing group $k$ 's vector of income by $\mu(k)$ and assessing the reduction in inequality induced by this. This procedure is repeated for each group and the average contribution of each group over all possible orderings of groups is computed. The last step is necessary to eliminate the effect of sequencing [19]. Apart from the issue of "subgroup inconsistency" which is a fundamental property of the Gini index [43], the application of the Shapley value approach to subgroup decomposition of the Gini index is appealing. However, its application in decomposing the Gini index by income components, which is not considered in this paper, remains highly debated [42, 44]. An attempt to resolve the debate is developed by Hierro and colleagues [41] and later applied to health financing [40].

\subsection{Decomposing the Redistributive Effect into Between-Group and Within-Group Components}

Using the Gini index as a measure of income inequality, and using the results in Eq. (4), we can rewrite Eq. (1) as:

$$
\begin{aligned}
R E & =\Delta G=\left(G_{X}^{B}+G_{X}^{W}\right)-\left(G_{X-T}^{B}+G_{X-T}^{W}\right), \\
& =\underbrace{\left(G_{X}^{B}-G_{X-T}^{B}\right)}_{\text {Between-group }}+\underbrace{\left(G_{X}^{W}-G_{X-T}^{W}\right)}_{\text {Within-group }}, \\
& =\Delta G^{B}+\Delta G^{W},
\end{aligned}
$$

where $G_{X}^{B}$ represents inequality in prepayment income between population subgroups, $G_{X}^{W}$ is the prepayment income inequality within population subgroups while $G_{X-T}^{B}$ and $G_{X-T}^{W}$ represent the post healthcare payment equivalents, respectively.

As shown in Eq. (7), $\Delta G^{B}$ is defined as the redistributive effect of healthcare payments between groups and $\Delta G^{W}$ is the corresponding effect within groups. The relative contributions of these components (i.e. $\left(\frac{\Delta G^{B}}{R E}\right)$ or $\left.\left(\frac{\Delta G^{W}}{R E}\right)\right)$ provide an indication of which component 'dominates'. A positive overall redistribution can result from a negative redistribution within-groups if this is sufficiently dominated by a positive redistribution between-group and vice versa. The various possible values of $\Delta G^{B}$ and $\Delta G^{W}$ are provided in Table 1 .

Given that the number of subgroups, $N \geq 2$, we noted earlier that $G^{W}=\sum_{i=1}^{N} G_{i}^{W}$ where $G_{i}^{W}$ is the decomposed inequality within group $i$. Thus, $\Delta G^{W}=\sum_{i=1}^{N} \Delta G_{i}^{W}$. This means that the redistribution of income within population subgroups $\left(\Delta G^{W}\right)$ is the sum of the redistribution that occurs within all population subgroups. Therefore, we can re-write Eq. (7) as follows:

$R E=\Delta G^{B}+\sum_{i=1}^{N} \Delta G_{i}^{W}$, 


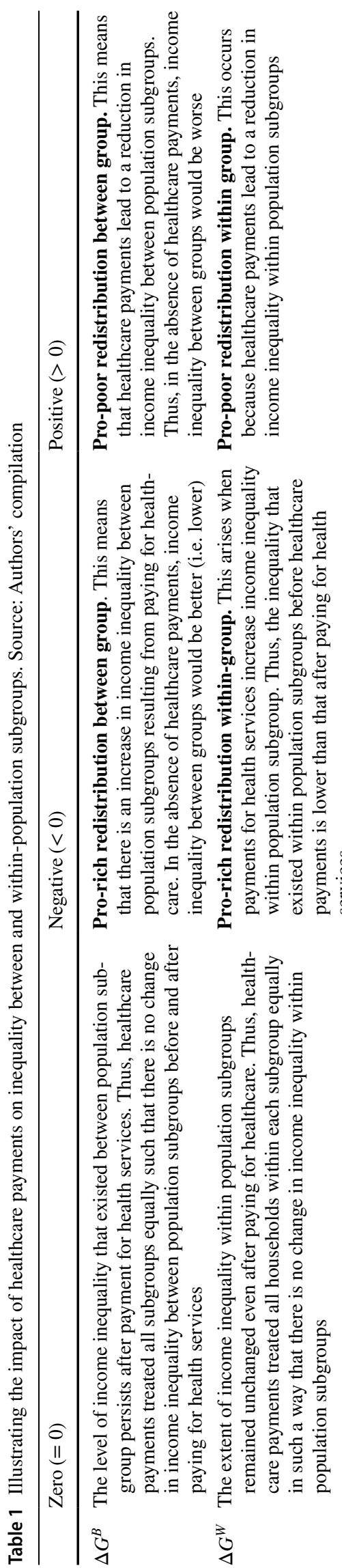

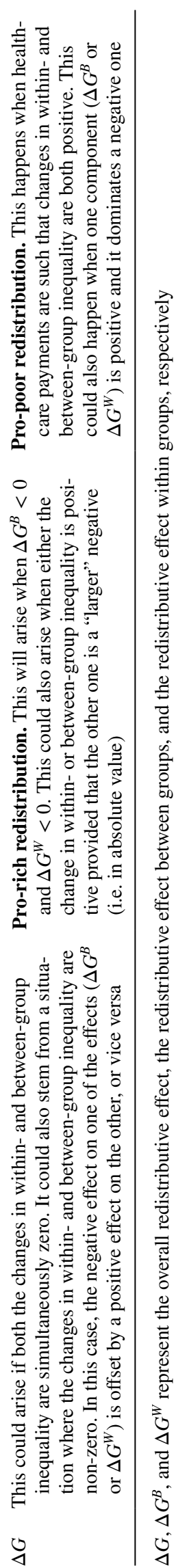

where $\Delta G_{i}^{W}$ is the decomposed redistribution of income within group $i$.

Table 2 provides a summary of the processes involved in decomposing the redistributive effect of health financing by groups.

\section{Empirical Application: The Case of Out-of-Pocket Payments in Nigeria}

Nigeria has a tiered health system with both the private and public health sectors. The country is one of the many African countries where out-of-pocket payments account for a substantial portion of current health expenditures. In 2000, out-of-pocket payments accounted for about $73 \%$ of current health expenditures in Nigeria [3]. The share of out-ofpocket payments has remained relatively high over the last two decades. In 2016, it accounted for over $75 \%$ of current health expenditures, one of the highest in the sub-Saharan Africa region [3]. As shown in Table 3, government's prioritisation of the health sector has remained low with domestic general government health expenditure as a proportion of general government expenditure hovering between 2 and $5 \%$ over the last 2 decades [3]. This is far less than the $15 \%$ threshold agreed upon by health ministers in Africa (i.e. the Abuja Declaration) [46].

Health insurance (voluntary and mandatory) in Nigeria is relatively underdeveloped. In 2005, the government of Nigeria initiated the National Health Insurance Scheme (NHIS). Presently, the NHIS under the Formal Sector Social Health Insurance Programme (FSSHIP) (i.e. one of the many programmes under the NHIS and the one that has been fully developed), covers less than $5 \%$ of the total population, mainly federal government civil servants and formal privatesector employees [47]. Contributions to the FSSHIP come from employers and employees (10\% and 5\% of basic salaries, respectively). Unfortunately, the NHIS has not guaranteed significant reductions in out-of-pocket payments, as shown in Table 3. This high share of out-of-pocket payments in health financing makes Nigeria an interesting case study. It is important to note that the framework developed in this paper can also be applied to other financing mechanisms and the entire health financing system and not limited to out-ofpocket payments.

\subsection{Data}

This paper uses the most recent nationally representative Harmonised Nigeria National Living Standard Survey (HNLSS) 2008/2009 conducted by the National Bureau of Statistics. A two-stage cluster sample design was used to collect the HNLSS data. Unlike the previous round, the 
Table 2 Summary of steps to assess the impact of healthcare payments on inequality between- and within-population subgroups. Source: Authors' compilation

\begin{tabular}{|c|c|c|}
\hline Step & Activity & Data source \\
\hline 1 & $\begin{array}{l}\text { Obtain a representative survey dataset that contains data on a measure of income, health service pay- } \\
\text { ments and the relevant groups (e.g. rural vs urban population). If health service payments are not } \\
\text { reported directly, these can be extracted as described in Ataguba, Asante [45] }\end{array}$ & \multirow{7}{*}{$\begin{array}{l}\text { Possible datasets include the } \\
\text { Income and Expenditure } \\
\text { Survey, Household Budget } \\
\text { Survey, Living Standards } \\
\text { Measurement Survey, etc. }\end{array}$} \\
\hline 2 & $\begin{array}{l}\text { Estimate the post-payment income for any healthcare payment (e.g. out-of-pocket payments) by subtract- } \\
\text { ing healthcare payments from pre-payment income for each household }\end{array}$ & \\
\hline 3 & $\begin{array}{l}\text { Compute per capita or per adult equivalent variables (pre-payment and post-payment income) to adjust } \\
\text { for household size, composition, etc. (see } 45 \text {, for more details) }\end{array}$ & \\
\hline 4 & $\begin{array}{l}\text { Estimate the redistributive effect of healthcare payments }\left(\Delta G=G_{X}-G_{N}\right) \text { for each health financing } \\
\text { mechanism. This is simply the difference between the pre-payment income inequality }\left(G_{X}\right) \text { and the } \\
\text { post-payment income inequality }\left(G_{N}\right) \text { for that health financing mechanism }\end{array}$ & \\
\hline 5 & $\begin{array}{l}\text { For the selected grouping (e.g. rural/urban), estimate the Gini index of between-group income inequality } \\
\text { for both pre-payment income }\left(G_{X}^{B}\right) \text { and post-payment income }\left(G_{X-T}^{B}\right) \text { using the Shapley value approach }\end{array}$ & \\
\hline 6 & $\begin{array}{l}\text { Similarly, for the selected grouping (e.g. rural/urban), estimate the Gini index of within-group income } \\
\text { inequality for both pre-payment income }\left(G_{X}^{W}\right) \text { and post-payment income }\left(G_{X-T}^{W}\right) \text { using the Shapley value } \\
\text { approach }\end{array}$ & \\
\hline 7 & $\begin{array}{l}\text { Compute the redistributive effect between groups, } \Delta G^{B}=G_{X}^{B}-G_{X-T}^{B} \text { and the redistributive effect within } \\
\text { groups, } \Delta G^{W}=G_{X}^{W}-G_{X-T}^{W} \text { using the information from steps } 5 \text { and } 6\end{array}$ & \\
\hline
\end{tabular}

Table 3 Health expenditure and financing in Nigeria, 2000-2016. Source: World Health Organization [3]

\begin{tabular}{|c|c|c|c|c|c|c|}
\hline & 2000 & 2005 & 2010 & 2014 & 2015 & 2016 \\
\hline Domestic Health Expenditure (DOM) as \% of Current Health Expenditure (CHE) & 95.36 & 97.47 & 93.67 & 87.86 & 90.06 & 89.70 \\
\hline External Health Expenditure (EXT) as \% of CHE & 4.64 & 2.53 & 6.33 & 12.14 & 9.92 & 9.83 \\
\hline Domestic General Government Health Expenditure (GGHE-D) as \% CHE & 20.12 & 17.89 & 13.76 & 13.40 & 16.49 & 13.02 \\
\hline Domestic Private Health Expenditure (PVT-D) as \% CHE & 75.24 & 79.59 & 79.91 & 74.46 & 73.57 & 76.67 \\
\hline Voluntary Health Insurance (VHI) as \% of CHE & 0.00 & 0.00 & 0.00 & 0.05 & 0.58 & 0.65 \\
\hline Out-of-pocket (OOP) payments as \% of CHE & 72.93 & 77.73 & 77.75 & 72.29 & 72.08 & 75.21 \\
\hline GGHE-D as \% General Government Expenditure (GGE) & 2.15 & 3.57 & 2.69 & 3.52 & 5.32 & 5.01 \\
\hline GGHE-D as \% Gross Domestic Product (GDP) & 0.53 & 0.68 & 0.45 & 0.45 & 0.59 & 0.47 \\
\hline
\end{tabular}

data were collected in two parts. The first part contains socio-demographic characteristics of households and individuals while the second part contains information on the living standards of households (i.e. household consumption expenditure and income). For the first part, ten enumeration areas (EAs) were selected from each of the 774 local government areas in Nigeria, bringing it to a total of 7740 EAs. The second stage randomly selected 10 housing units from each EA. After data cleaning, the final sample size was about 73,329 housing units (i.e. $94.7 \%$ response rate) [48]. The second part consists of a reduced but nationally representative sample (about 35,000 households). Here, 5 housing units were randomly selected from the original 10 housing units in each of the $7740 \mathrm{EA}$. Thus, the second part is a subset of households contained in the first part [48]. Sampling weights are based on the sampling strategy to ensure that the data are representative at the national and sub-national levels.

Household income, used as a measure of standard of living, was proxied by household consumption obtained from the HNLSS. Total out-of-pocket expenditures comprise direct payments at the point of using health services (public and private), which are then not reimbursed by any prepayment scheme. These have been extracted from the HNLSS to include direct expenditures on consultations (outpatient health service use), hospital admission costs (inpatient healthcare costs), medicines and supplies related to admissions and outpatient services, drugs, medicine and medical supplies, and maternal and child health services. These expenditures have been annualised to ensure consistency with household income recorded on an annual basis. Specifically, out-of-pocket payments data were obtained from responses to the various questions in Sect. 3 of the HNLSS data that relate to direct payments for health services (see "Appendix").

Household income and out-of-pocket expenditures were adjusted to account for variations in household size and composition $[49,50]$ by equivalising by the adult equivalence scale represented as: 
$A E=\left(n_{A}+\alpha n_{k}\right)^{\theta} \quad$ for $0<\alpha \leq 1 ; 0<\theta \leq 1$

where $n_{A}$ is the number of adults in the household; $n_{k}$ is the number of children (aged $<15$ years), $\alpha$ is the cost of children (a measure of the weight accorded to children relative to that accorded to adults) $[51,52]$ and $\theta$ represents a measure of economies of scale. Adult equivalent income and payments were computed using the values $\alpha=1$ and $\theta=1$, which in essence represent per capita estimates [53].

Nigeria has 36 states and the federal capital territory. However, the mutually exclusive groups identified for analysis in this paper are the 6 geopolitical zones in NigeriaNorth East, North West, North Central, South East, South West and South South. These zones represent significant grouping in Nigeria, relating to economic, social and political issues in the country.

\subsection{Estimation Strategy}

Recall from Eq. (7) that $R E=\Delta G^{B}+\Delta G^{W}$. The overall redistributive effect $(\Delta G)$ was computed in Stata 15 [54] using the Distributive Analysis Stata Package (DASP) software $[55,56]$. The Shapley value approach [see Eq. (4)] was used to decompose the Gini indices into between- and within-group inequality for both prepayment and post healthcare payment incomes $\left(G_{X}^{B}, G_{X}^{W}, G_{X-T}^{B}\right.$ and $\left.G_{X-T}^{W}\right)$. These indices were used to compute the components of Eq. (7).

Empirically, the Gini index was computed as:

$G=1-(\hat{\xi} / \hat{\mu})$,

where $\hat{\xi}=\sum_{i=1}^{n}\left(\left(\left(V_{i}\right)^{2}-\left(V_{i+1}\right)^{2}\right) /\left(V_{1}\right)^{2}\right) x_{i} ; V_{i}=\sum_{h=i}^{n} w_{h}$ and $x_{1} \geq x_{2} \geq \cdots \geq x_{n}$.

The vector $\mathrm{w}=\left[w_{1}, w_{2}, \ldots, w_{n}\right]$ represents the sampling weights while the vector, $\mathbf{X}$, such that $x_{1} \geq x_{2} \geq \cdots \geq x_{n-1} \geq x_{n}$ represents gross per capita incomes. The weighted average of per capita incomes is $\hat{\mu}$.

The asymptotic standard error for $G_{X}, G_{X-T}$ and $\Delta G$ can be obtained analytically using the DASP suite [56] taking into account the fact that $\Delta G$ is estimated from the same sample or dataset with some joint sampling distribution. However, the standard errors for $\Delta G^{B}$ and $\Delta G^{W}$ are obtained using the bootstrap methods with 1000 resamples or replications [57, 58] taking into account the full sampling structures and the fact that these are obtained from the same sample (i.e. re-sampling is done by clusters as opposed to using individual points directly).

\section{Results and Discussion}

The results of the indices $\left(G_{X}^{B}, G_{X}^{W}, G_{X-T}^{B}\right.$ and $\left.G_{X-T}^{W}\right)$ introduced in Eq. (7) are contained in Table 4. Briefly, the level of income inequality in Nigeria, measured by the Gini index,
Table 4 Inequality between and within groups (geopolitical zones), Nigeria, 2009. Source: Authors' computation

\begin{tabular}{lll}
\hline & $G_{X}$ & $G_{X-T}$ \\
\hline Between group $(B)$ & $7.8624 * *(0.4098)$ & $7.8636 * * *(0.4108)$ \\
Within group $(W)$ & $40.6638 * * *(0.4772)$ & $40.6858 * * *(0.4776)$ \\
Overall $(G)$ & $48.5262 * * *(0.3930)$ & $48.5494 * * *(0.3926)$ \\
$(B / G) \%$ & $16.2 \%$ & $16.2 \%$ \\
$(W / G) \%$ & $83.8 \%$ & $83.8 \%$ \\
\hline
\end{tabular}

All estimates have been multiplied by 100 to enhance readability

$G_{X}$ and $G_{X-T}$ are the Gini index of gross income and post-payment income (i.e. post out-of-pocket payments), respectively

Standard errors in parenthesis_-bootstrapped using 1000 replications $* * * p<0.01$

using per capita household consumption was estimated at 0.4853 before paying out-of-pocket for health services. Post out-of-pocket payments, income inequality increased to 0.4855 . A similar pattern was seen for both betweenand within-group (geo-political zones) income inequality in Nigeria, with $G_{X}<G_{X-T}$. The inequality within groups dominates substantially ( $>83 \%$ ) for both inequality in prepayment and post-payment income. In fact, the Gini index estimated in this paper $(0.4853)$ was similar to that $(0.45)$ reported by the National Bureau of Statistics (NBS) in Nigeria, although the NBS may have used per capita expenditure as opposed to per capita consumption [59]. The NBS also reports the Gini indices across the six geo-political zones in Nigeria [59].

The empirical results of the redistributive effect of out-ofpocket payments in Nigeria into within and between groups using the revised framework are shown in Table 5. These results indicated that financing health services out-of-pocket contributed to significant increases in income inequality in Nigeria. The overall redistributive effect $(R E)$ considering out-of-pocket payments was estimated at -0.0002 and this was statistically significant at the $5 \%$ level of significance. Using a subgroup of the six geopolitical zones in Nigeria, it emerged that there was a negative redistributive effect occurring both between and within groups because of financing health services out-of-pocket in Nigeria. Stated differently, income inequality within and between subgroups had increased due to out-of-pocket healthcare payments in Nigeria. However, these increases in between- and withingroup income inequality are not statistically significant at conventional levels of significance.

These results show that in the absence of out-of-pocket payments, for instance, income inequality would have been lesser both within and between the six geopolitical zones in Nigeria.

Although income inequality increased both between and within groups, the contribution of the pro-rich 
Table 5 Decomposing the redistributive effect of out-of-pocket payments into between and within groups (geopolitical zones), Nigeria, 2009. Source: Authors' computation

\begin{tabular}{llllc}
\hline Financing mechanism & $R E$ & $\Delta G^{B}$ & $\Delta G^{W}$ & $\left(\frac{\Delta G^{B}}{R E}\right) \%$ \\
\hline Out-of-pocket payments & $-0.0233^{* *}(0.0107)$ & $-0.0012(0.0093)$ & $-0.0220(0.0124)$ & $5.17 \%$ \\
\hline
\end{tabular}

All estimates have been multiplied by 100 to enhance readability

Standard errors in parenthesis-bootstrapped using 1000 replications for $\Delta G^{B}$ (the redistributive effect between groups) and $\Delta G^{W}$ (the redistributive effect within groups). Analytical standard errors for the redistributive effect $(R E)$

$* * p<0.05$

redistributive effect within groups $\left(\Delta G^{W}\right)$ to overall income redistributive effect of out-of-pocket payments in Nigeria was greater than the negative redistributive effect occurring between groups $\left(\Delta G^{B}\right)$. In summary, it was estimated that about $95 \%$ of the redistributive effect of out-of-pocket payments in Nigeria was associated with the negative redistributive effect within the six geopolitical zones. Changes in income inequality between groups accounted for only about $5 \%$ of the total redistributive effect of out-of-pocket payments in Nigeria.

Further decomposition of the redistributive effect of out-of-pocket healthcare payments within groups (Table 6) showed that changes in inequality within the North West zone dominated overall changes in income inequality in Nigeria. This change was significant and estimated at -0.0001 . This was followed by the South West zone, but this result was not statistically significant.

The results from Nigeria demonstrated that the significant contribution of out-of-pocket healthcare payments to increased income inequality in the country was caused mainly by how such payments contributed to changes in income inequality within geopolitical zones. The share that was caused by changes in income inequality between groups was relatively small. This result cannot be obtained from using the existing framework that only shows the relative importance of $V, H$ and $R$ in total redistribution, which are also important in their own regards.

This paper demonstrated that the potential widening of income inequality caused by out-of-pocket payments needs to be addressed to reduce income inequality significantly. If the government is committed to reductions in income inequality in Nigeria, it should not just aim to reduce the share of out-of-pocket payments in current health expenditures. It should also aim to ensure that financing health services, especially where out-of-pocket payments may still exist, should substantially reduce income inequality, especially within each geopolitical zone. Traditionally, this can be achieved using exemptions and the provision of free health services for households that are unable to afford the use of health services. It means that regional specific policies that address the high level and disparities in out-ofpocket healthcare payments within regions in the country are needed. In the context of Nigeria, it was shown that the North West zone, one of the poorest zones in the country [60], contributes substantially more to changes in withingroup income inequality that were associated with out-ofpocket healthcare payments. This highlights the importance of that zone in reducing overall income inequality in Nigeria.

Table 6 Decomposing the contributions of different subgroups (geopolitical zones) to total within-group inequality $\left(\Delta G^{W}\right)$, Nigeria, 2009 . Source: Authors' computation

\begin{tabular}{|c|c|c|c|c|c|c|}
\hline & North Central & North East & North West & South East & South South & South West \\
\hline$G_{X}^{W}$ & $\begin{array}{r}6.1090 * * * \\
(0.3610)\end{array}$ & $\begin{array}{r}4.3005^{* * * *} \\
(0.2400)\end{array}$ & $\begin{array}{r}7.8376 * * * \\
(0.3182)\end{array}$ & $\begin{array}{r}5.8413 * * * \\
(0.4127)\end{array}$ & $\begin{array}{r}7.1721 * * * \\
(0.3876)\end{array}$ & $9.4031 * * *(0.3946)$ \\
\hline$G_{X-T}^{W}$ & $\begin{array}{r}6.1077 * * * \\
(0.3605)\end{array}$ & $\begin{array}{r}4.3006 * * * \\
(0.2398)\end{array}$ & $\begin{array}{r}7.8510 * * * \\
(0.3185)\end{array}$ & $\begin{array}{r}5.8433 * * * \\
(0.4126)\end{array}$ & $\begin{array}{r}7.1717 * * * \\
(0.3880)\end{array}$ & $9.4115 * * *(0.3946)$ \\
\hline$\Delta G^{W}=G_{X}^{W}-G_{X-T}^{W}$ & $0.0013(0.0063)$ & $-0.0001(0.0048)$ & $\begin{array}{c}-0.0134 * * * \\
(0.0050)\end{array}$ & $-0.0020(0.0081)$ & $0.0004(0.0058)$ & $-0.0084(0.0052)$ \\
\hline $\begin{array}{l}\% \text { share of } \Delta G^{W} \\
\text { in each zone to } \\
\text { overall } \Delta G^{W}\end{array}$ & $-5.9 \%$ & $0.5 \%$ & $60.4 \%$ & $9.0 \%$ & $-1.8 \%$ & $37.8 \%$ \\
\hline$\left(\Delta G^{W} / \Delta R E\right) \%$ & $-5.6 \%$ & $0.4 \%$ & $57.2 \%$ & $8.5 \%$ & $-1.7 \%$ & $35.9 \%$ \\
\hline
\end{tabular}

All estimates have been multiplied by 100 to enhance readability

$* * * p<0.01$; bootstrapped standard errors (using 1000 replications) in parenthesis

$\Delta G^{W}$ is the redistributive effect within groups; $G_{X}^{W}$ and $G_{X-T}^{W}$ represent income inequality within population subgroups, pre and post-out-ofpocket payments, respectively 
Given the relative size of Nigeria and the relative share of changes in within-group income inequality caused by paying out-of-pocket for health services, there is a need for health financing reforms, e.g. through the NHIS, to concentrate on states and zones to reduce income inequality. Indeed, and as noted earlier, the current NHIS policy has largely targeted federal civil servants without significant attention to regional disparities. The NHIS, since its introduction in 2005 had covered only less than 5\% of the population in Nigeria [47]. It is only recently that a few states in Nigeria have started setting up state health insurance structures to cover their populations, including the substantial numbers in the informal economy. With reductions in out-of-pocket healthcare payments and a movement towards an equitable pre-payment system, the contributions of out-of-pocket healthcare payments to income inequality will reduce substantially in Nigeria.

This paper has a few limitations. The first relates to the dataset used to compute household income and out-of-pocket payments. It uses the recall as opposed to the diary method. Also, the methods proposed for assessing the redistributive effect of healthcare payments do not account for migration between geopolitical zones and how that affects the use and payment for health services. The reported out-of-pocket payments cannot be traced to the zone where utilisation occurred. While the occurrence of such may be very negligible in the case of this paper, it is essential to understand this impact in each study that may apply the framework.

\section{Conclusion}

An assessment of the income redistributive effect of health financing is vital for the design of financing arrangements that ensure equitable treatment of households. Traditional assessment approaches used to decompose the impact of health financing on income inequality focus on estimating the vertical effect (i.e. the extent of progressivity); horizontal effect (i.e. the extent to which households with similar incomes are treated equally when financing health services); and reranking effect (i.e. whether households change their relative socio-economic ranking after financing health services). While such decompositions are useful in pointing to areas where policy interventions are needed, they do not tell us much about changes in income inequalities between and within population groups. In pluralistic countries, it is essential to understand how, by paying for health services, different population subgroups contribute to widening or reducing income inequality. For example, it is very crucial to answer questions like: do payments for health services widen income inequality between or within population groups in a country? Which province or region within a country contributes more to changes in income inequality associated with health financing? etc. This is where the paper makes significant contributions to the literature on the assessment of the income redistributive effect of health financing.

Acknowledgements The authors acknowledge the funding received from the African Economic Research Consortium (AERC) and the National Research Foundation's South African Research Chairs Initiative (SARChI) Communities of Practice Initiative. We also thank Dr Abdelkrim Araar, of Laval University, Canada, for providing the initial Stata Ado file that was modified and used for the Shapley value decomposition analysis. JEA is supported by the South African Research Chairs Initiative of the Department of Science and Technology and National Research Foundation.

Author Contributions JEA, HEI, CON and JA conceived the research; JEA sourced and analysed the data; JEA, HEI, CON and JA contributed to reviewing the literature, interpreting the results and drafting the paper; JEA, HEI, CON and JA read and approved the final submission.

Data Availability The datasets analysed during the current study are available in the Nigeria National Bureau of Statistics' repository, http:// www.nigerianstat.gov.ng/nada/index.php/catalog/38

\section{Compliance with Ethical Standards}

Ethical Standards This paper uses publicly available data that have received ethics approval. Thus, there are no ethical issues.

Conflict of interest JEA, HEI, CON and JA have no conflicts of interests to declare.

Open Access This article is distributed under the terms of the Creative Commons Attribution-NonCommercial 4.0 International License (http://creativecommons.org/licenses/by-nc/4.0/), which permits any noncommercial use, distribution, and reproduction in any medium, provided you give appropriate credit to the original author(s) and the source, provide a link to the Creative Commons license, and indicate if changes were made.

\section{Appendix: Household Survey Questions Used to Elicit Data on Out-of-Pocket Payments}

\section{Part 3A: Health Conditions}

Q14: How much did [NAME] pay for the first trip (to and from) for consultation (transport costs)?

Q13: How much did [NAME] pay for the first consultation?

Q17: How much did [NAME]pay for the drugs over the counter or kiosks?

Q20: How much did [NAME] pay for staying in hospital or health centre?

Q22: How much did [NAME] pay altogether for these medicines and medical supplies?

Q24: Apart from what was paid by others, how much did [NAME] pay out of his/her own pocket for medical service? 


\section{Part 3B: Malaria}

Q9: How much did [NAME] pay for primary level consultation during this episode (excluding drugs)?

Q13: How much did [NAME] pay for hospitalisation (excluding transportation and drug cost)?

Q17: How much did [NAME] pay for the medicine?

Q20: How much did [NAME] pay for transportationrelated to illness?

\section{Part 3D: Preventive Health and Vaccination}

Q10: How much did [NAME] pay for the last vaccination?

\section{Part 3E: Maternal Health Services}

Q28: How much did [NAME] pay for that (contraceptive) during the last month?

Q23: How much did [NAME] pay for the first pre-natal or post-natal consultation?

\section{References}

1. Ataguba JE, Ingabire M-G. Universal Health Coverage: Assessing Service Coverage and Financial Protection for All. Am J Public Health. 2016;106(10):1780-1.

2. Mills A, Ataguba JE, Akazili J, Borghi J, Garshong B, Makawia $S$, et al. Equity in financing and use of healthcare in Ghana, South Africa, and Tanzania: implications for paths to universal coverage. The Lancet. 2012;380(9837):126-33.

3. Global Health Expenditure Database [Internet]. World Health Organization. 2019. Available from: http://apps. who.int/nha/datab ase/ViewData/Indicators/en.

4. Ataguba JE. Reassessing catastrophic healthcare payments with a Nigerian case study. Health Economics, Policy and Law. 2012;7(3):309-26.

5. Wagstaff A, van Doorslaer E. Catastrophe and impoverishment in paying for healthcare: with applications to Vietnam 1993-98. Health Econ. 2003;12(11):921-33.

6. O'Donnell O, van Doorslaer E, Rannan-Eliya RP, Somanathan A, Adhikari SR, Akkazieva B, et al. Who pays for healthcare in Asia? Journal of Health Economics. 2008;27(2):460-75.

7. Ichoku HE. A distributional analysis of healthcare financing in a developing country: a Nigerian case study applying a decomposable Gini index. Cape Town: $\mathrm{PhD}$ thesis, University of Cape Town; 2006.

8. van Doorslaer E, Wagstaff A, van der Burg H, Christiansen T, Citoni G, Di Biase R, et al. The redistributive effect of healthcare finance in twelve OECD countries. Journal of Health Economics. 1999;18(3):291-313.

9. Ichoku HE, Fonta WM, Araar A. A Distributional Analysis of outof-pocket Healthcare Financing in Nigeria Using a New Decomposable Framework. Central Bank of Nigeria Journal of Applied Statistics. 2011;1:71-83.

10. Mulenga A, Ataguba JE. Assessing income redistributive effect of health financing in Zambia. Soc Sci Med. 2017;189:1-10.

11. Gerdtham U-G, Sundberg G. Redistributive effects of Swedish healthcare finance. The International Journal of Health Planning and Management. 1998;13(4):289-306.
12. Leung GM, Tin KYK, O’Donnell O. Redistribution or horizontal equity in Hong Kong's mixed public-private health system: a policy conundrum. Health Econ. 2009;18(1):37-54.

13. Zhong $\mathrm{H}$. Extensions to decomposition of the redistributive effect of healthcare finance. Health Econ. 2009;18(10):1176-87.

14. Musgrave RA, Thin T. Income tax progression, 1929-48. The Journal of Political Economy. 1948;56(6):498-514.

15. Reynolds M, Smolensky E. Public expenditures, taxes, and the distribution of income: the United States 1950, 1961, 1970. New York: Academic Press; 1977.

16. Aronson JR, Johnson P, Lambert PJ. Redistributive effect and unequal income tax treatment. Economic Journal. 1994;104(423):262-70.

17. O'Donnell O, Van Doorslaer E, Wagstaff A, Lindelow M. Analyzing health equity using household survey data: a guide to techniques and their implementation. Washington DC.: World Bank; 2008.

18. Kakwani NC. Measurement of tax progressivity: an international comparison. Econ J. 1977;87(345):71-80.

19. Duclos J-Y, Araar A. Poverty and equity: measurement, policy, and estimation with DAD. Berlin and Ottawa: Springer and IDRC; 2006.

20. Wagstaff A, van Doorslaer E. Progressivity, horizontal equity and reranking in healthcare finance: a decomposition analysis for the Netherlands. Journal of Health Economics. 1997;16(5):499-516.

21. Abu-Zaineh M, Mataria A, Luchini S, Jean-Paul M. Equity in healthcare finance in Palestine: the triple effects revealed. Journal of Health Economics. 2009;28(6):1071-80.

22. Urban I, Lambert PJ. Redistribution, horizontal inequity, and reranking: how to measure them properly. Public Finance Review. 2008;36(5):563-87.

23. van de Ven J, Creedy J, Lambert PJ. Close equals and calculation of the vertical, horizontal and reranking effects of taxation. Oxford Bulletin of Economics and Statisitics. 2001;63(3):381-94.

24. Duclos J-Y, Jalbert V, Araar A. Classical Horizontal Inequity and reranking: an Integrated approach. In: Amiel Y, Bishop JA, editors. Fiscal policy, inequality and welfare (Research on economic inequality volume 10). 10. Bingley: Emerald Group 2003. p. 65-100.

25. wa Mogoeng M. Law and Religion in Africa: The quest for the common good in pluralistic societies. In: Coertzen P, Green MC, Hansen L, editors. Law and Religion in Africa: The quest for the common good in pluralistic societies. Stellenbosch: Africa Sun Media; 2015.

26. Bourguignon F. Decomposable income inequality measures. Econometrica. 1979;47:901-20.

27. Gini C. Sulla misura della concentrazione e della variabilità dei caratteri. Atti del Reale Istituto Veneto di Scienze. Lettere ed Arti. 1914;73(2):1203-48.

28. Gini C. Variabilità e Mutuabilità: Contributo allo studio delle distribuzioni e delle relazioni statistiche. Bologna: Tipografia di Paolo Cuppin; 1912.

29. Soltow L. The distribution of income related to changes in the distributions of education, age, and occupation. The Review of Economics and Statistics. 1960:450-3.

30. Bhattacharya N, Mahalanobis B. Regional disparities in household consumption in India. Journal of the American Statistical Association. 1967;62(317):143-61.

31. Pyatt G. On the interpretation and disaggregation of Gini coefficients. Econ J. 1976;86(342):243-55.

32. Cowell FA. On the structure of additive inequality measures. The Review of Economic Studies. 1980;47(3):521-31.

33. Blackorby C, Donaldson D, Auersperg M. A new procedure for the measurement of inequality within and among population subgroups. Canadian Journal of Economics. 1981:665-85. 
34. Silber J. Factor components, population subgroups and the computation of the Gini index of inequality. The Review of Economics and Statistics. 1989:107-15.

35. Lambert PJ, Aronson JR. Inequality decomposition analysis and the Gini coefficient revisited. Econ J. 1993;103(420):1221-7.

36. Deutsch J, Silber J. Inequality decomposition by population subgroups and the analysis of interdistributional inequality. Handbook on Income Inequality Measurement. Dordrecht and Boston: Kluwer Academic Press; 1999.

37. Deutsch J, Silber J. On the Shapley value and the decomposition of inequality by population subgroups with special emphasis on the Gini index. In: Betti G, Lemmi A, editors. Advances on Income Inequality and Concentration Measures. London and New York: Routledge; 2008. p. 161.

38. Araar A. On the decomposition of the Gini coefficient: an exact approach, with an illustration using Cameroonian data. CIRPÉE Working Paper 06-02. Quebec: University of Laval; 2006.

39. Shapley L. A value for n-person games. In: Kuhn HW, Tucker AW, editors. Contributions to the Theory of Games. 2. New Jersey: Princeton University Press; 1953. p. 307-17.

40. Hierro L, Gómez-Álvarez R, Atienza P. A consistent decomposition of the redistributive, vertical, and horizontal effects of healthcare finance by factor components. Health Econ. 2014;2014(23):117-21.

41. Hierro L, Gómez-Álvarez R, Atienza P. The contribution of US taxes and social transfers to income redistribution. Public Finance Review. 2012;40(3):381-400.

42. Cowell FA, Fiorio CV. Inequality decompositions-a reconciliation. The Journal of Economic Inequality. 2011;9(4):509-28.

43. Shorrocks AF. Decomposition procedures for distributional analysis: a unified framework based on the Shapley value. Journal of Economic Inequality. 2013:1-28.

44. Sastre M, Trannoy A. Shapley inequality decomposition by factor components: some methodological issues. J Econ. 2002;77(1):51-89.

45. Ataguba JE, Asante AD, Limwattananon S, Wiseman V. How to do (or not to do)... a health financing incidence analysis. Health Policy and Planning. 2018;33(3):436-44.
46. Organization of African Unity. Abuja declaration on HIV/AIDS, tuberculosis and other related infectious diseases. Addis Ababa: Organization of African Unity; 2001.

47. Uzochukwu B, Ughasoro M, Etiaba E, Okwuosa C, Envuladu E, Onwujekwe O. Healthcare financing in Nigeria: Implications for achieving universal health coverage. Nigerian Journal of Clinical Practice. 2015;18(4):437-44.

48. National Bureau of Statistics. Harmonized Nigeria Living Standard Survey (HNLSS) 2008/2009. Abuja: National Bureau of Statistics; 2010

49. Coulter FAE, Cowell FA, Jenkins SP. Equivalence scale relativities and the extent of inequality and poverty. Econ J. 1992;102:1067-82.

50. Deaton A. The analysis of household surveys. Baltimore: The Johns Hopkins University Press; 1997.

51. Banks J, Johnson P. Equivalence scale relativities revisited. Econ J. 1994;104(425):883-90.

52. Citro CF, Michael RT. Measuring poverty: a new approach. Washington D.C: National Academy Press; 1995.

53. Deaton A, Zaidi S. Guidelines for constructing consumption aggregates for welfare analysis. LSMS Working Paper No 135. Washington D.C.: World Bank Publications; 2002.

54. StataCorp. Stata: release 15 - Statistical software. College Station, Texas: StataCorp LP; 2017.

55. Araar A, Duclos J-Y. DASP: Distributive Analysis Stata package. Laval: PEP, CIRPÉE and World Bank, Université Laval; 2009.

56. Araar A, Duclos J-Y. User manual for Stata package DASP: version 2.1. Laval: PEP, World Bank, UNDP and Université Laval; 2009.

57. Efron B. Better bootstrap confidence intervals. Journal of the American Statistical Association. 1987;82:171-85.

58. Efron B, Tibshirani R. Bootstrap methods for standard errors, confidence intervals, and other measures of statistical accuracy. Statistical Science. 1986;1(1):54-75.

59. National Bureau of Statistics. Nigeria poverty profile 2010. Abuja: National Bureau of Statistics; 2012.

60. Anyanwu JC. Marital status, household size and poverty in Nigeria: evidence from the 2009/2010 survey data. African Development Review. 2014;26(1):118-37. 